\title{
25
}

\section{Categorizing distance learning systems: discovering successful ingredients}

\author{
Greg Jones
}

University of Texas

Austin

USA

Gerald Knezek

University of North Texas

Denton

USA

\begin{abstract}
The technology of a delivery system is only one of the factors of importance when examining what does and does not work in distance education. The characteristics of the teacher and learner, and the content to be delivered must also be examined before the delivery system is chosen, since these factors determine final learning outcomes. This paper provides a framework for categorizing distance learning systems and discusses specific examples of how teaching, learning and distance education technology interact to produce successful teaching-learning experiences.
\end{abstract}

Main conference themes: distance learning

Educational areas:

Study topics:

Secondary keywords: instruction, telecommunications, curriculum policies 


\section{INTRODUCTION}

The technology of a delivery system is only one of the factors of importance when examining what does and does not work in distance education. The characteristics of the teacher and learner, and the content to be delivered must also be examined before the delivery system is chosen, since these factors determine final learning outcomes. Research has shown that instructional methods which actively engage the student in the learning process are most successful [1]. The incorrect assumption is that higher bandwidth (greater capacity) in a delivery system which enables greater fidelity and interactivity, directly translates into better learning. This paper provides a framework for categorizing distance learning systems and discusses specific examples of how teaching, learning and distance education technology interact to produce successful teaching-learning experiences.

\section{DELIVERY SYSTEMS}

Potential delivery systems can be categorized according to three basic types: correspondence, broadcast and interactive. A correspondence system is any system where there is a significant time delay between instructor dissemination and student receipt of information. Methods in this category include Mail Correspondence (paper, video, CD-ROM) and Electronic Mail. Broadcast systems take advantage of some mass media communication channel in order to reach a larger population. This method typically allows many students access, but has limited or no feedback to the instructor. Examples of these systems include broadcast radio (FM, AM), broadcast satellite (video and audio), terrestrial broadcast television and cable/closed circuit television (public and private). The interactive method introduces some level of intimacy and information is delivered and returned in a more timely fashion (almost in real time). Such systems include normal telephone, telephone (audio) conferencing, two-way radio, slow scan television, Video Conferencing and Computer conferencing.

Based on these delivery systems a common categorization method can be established which takes into account Technology factors, Economic factors and Information Delivery factors. Figure 1 contains these categories along with additional teacher and learner factors which will be discussed later. Technology factors are availability, maintainability and compatibility. Economic factors include various costs, critical mass and support issues. Information Delivery focuses on the means of information delivery. It must be noted that these systems outlined are representations and that most existing delivery 
systems use some hybrid type to deliver instruction such as combining correspondence with broadcast or interactive types.

\begin{tabular}{|c|c|c|c|c|c|c|c|c|c|c|c|c|c|c|c|c|c|c|c|c|}
\hline \multirow[b]{3}{*}{$\begin{array}{l}\text { Potential } \\
\text { Delivery Systems }\end{array}$} & \multicolumn{11}{|c|}{ Delivery System } & \multirow{2}{*}{\multicolumn{3}{|c|}{ Instructor }} & \multicolumn{6}{|c|}{ Lecrmer } \\
\hline & \multicolumn{3}{|c|}{$\begin{array}{l}\text { Technology } \\
\text { Issues }\end{array}$} & \multicolumn{5}{|c|}{$\begin{array}{l}\text { Economic } \\
\text { Issues }\end{array}$} & \multicolumn{3}{|c|}{$\begin{array}{l}\text { Information } \\
\text { Flow Issues }\end{array}$} & & & & \multicolumn{3}{|c|}{$\begin{array}{l}\text { Learner's } \\
\text { Style }\end{array}$} & \multicolumn{3}{|c|}{$\begin{array}{l}\text { Cognitive } \\
\text { Factors }\end{array}$} \\
\hline & 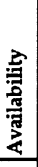 & 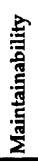 & 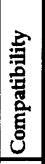 & 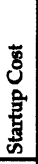 & 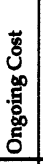 & 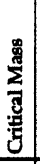 & 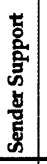 & 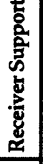 & 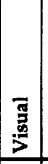 & 宮 & 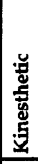 & 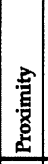 & 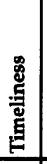 & 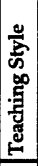 & 䋷 & 害 & 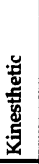 & 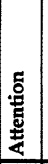 & 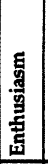 & 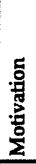 \\
\hline $\begin{array}{l}\text { Traditional Classroom } \\
\text { Instruction }\end{array}$ & 3 & 1 & 1 & 1 & 1 & 1 & 1 & 1 & 1 & 1 & 1 & 1 & 2 & & & & & & & \\
\hline Mail Corrcspondence & 1 & 1 & 1 & 1 & 2 & 1 & 2 & 1 & 2-1 & $2-1$ & 3 & 3 & 2 & & & & & & & \\
\hline Broadcast Radio (AM, FM) & 1 & 1 & 1 & 1 & 1 & 2 & 2 & 1 & 3 & $\mathbf{1}$ & 3 & 2 & 2 & & & & & & & \\
\hline 2-Way Radio & 1 & 2 & 1 & 1 & 1 & 1 & 1 & 1 & 3 & 1 & 3 & 2 & 1 & & & & & & & \\
\hline Telephone & 1 & 1 & 1 & 1 & 3 & 1 & 1 & 1 & 3 & 1 & $\mathbf{3}$ & 1 & 1 & & & & & & & \\
\hline Telephone Conferencing & 1 & 2 & 2 & 1 & 2 & 2 & 2 & 1 & 3 & 1 & 3 & 1 & 1 & & & & & & & \\
\hline Slow-Scan TV & 3 & 2 & 2 & 2 & 2 & 2 & 2 & 2 & 1 & 3 & 3 & 1 & 2 & & & & & & & \\
\hline Computer Elec Mail & 2 & 2 & 3 & 2 & 2 & 2 & 2 & 1 & $2 \cdot 1$ & 2-1 & 3 & 2 & 2 & & & & & & & \\
\hline Computer Conferencing & 2 & 2 & 3 & 2 & 2 & 2 & 2 & 1 & 2.1 & $2-1$ & 3 & 1 & 1 & & & & & & & \\
\hline Broadcast TV & 1 & 1 & 1 & 3 & 1 & 3 & 3 & 1 & 1 & 1 & 3 & 1 & 2 & & & & & & & \\
\hline Broadcast Satellite & 2 & 1 & 1 & 3 & 2 & 3 & 3 & 1 & 1 & 1 & $\mathbf{3}$ & 3 & 13 & & & & & & & \\
\hline VideoText & 3 & 2 & 3 & 3 & 2 & 2 & 3 & 1 & 2-1 & 2.1 & 3 & 3 & 12 & & & & & & & \\
\hline \multirow[t]{2}{*}{ Video Conferencing } & 3 & 1 & 1 & 3 & 3 & 2 & 3 & 3 & 1 & 1 & 3 & 1 & 1 & & & & & & & \\
\hline & \multicolumn{3}{|c|}{$\begin{array}{l}1=\text { High } \\
2=\text { Med } \\
3=\text { Low }\end{array}$} & \multicolumn{5}{|c|}{$\begin{array}{l}3=\text { Large } \\
2=\text { Avg } \\
1=\text { Small }\end{array}$} & \multicolumn{3}{|c|}{$\begin{array}{l}1=\text { Good } \\
2=\text { Poor } \\
3=\text { None }\end{array}$} & \multicolumn{3}{|c|}{$\begin{array}{l}1=\text { Good } \\
2=\text { Poor } \\
3=\text { None }\end{array}$} & \multicolumn{3}{|c|}{$\begin{array}{l}1=\operatorname{High} \\
2=\text { Med } \\
3=\text { Low }\end{array}$} & \multicolumn{3}{|c|}{$\begin{array}{l}1=\text { High } \\
2=\text { Mod } \\
3=\text { Low } \\
\end{array}$} \\
\hline
\end{tabular}

Fig. 1 Categorizing potential delivery systems by delivery system, instructor and learner

\section{Teacher and learner components/instructional components}

Wide bandwidth is a useful ingredient for the delivery of distance education, but is not the most critical component in the knowledge dissemination paradigm. The teacher and the learner must be examined in order to understand the complete model. The delivery systems listed above can be thought of as the information conduit between the instructor and learner. While much time and worry can be spent on the establishing and maintaining the delivery system, failure to place significant emphasis on the teacher and learner components can lead to a poor learning environment.

We can roughly organize instructional considerations into three factors: proximity (intimacy), timeliness of instruction and teaching style (lecture, seminar, etc.). Proximity relates to how the instructor and student interpret the intimacy of the process. Timeliness takes into account the information flow to and from the student. Some systems have more flow in one direction than the 
other. Both proximity and timeliness are determined by the type of delivery system although some slippage can occur based on the course style. Teaching style is mostly dependent on the teacher and the structure of the course, and cannot be significantly defined in this article. Finally we can divide learning considerations into learning styles and cognitive factors. Learning styles include: visual, auditory and kinaesthetic. Cognitive factors encompass items such as attention, enthusiasm and motivation. Cognitive factors are dependent on each student and cannot be determined solely based on the delivery system.

\section{Strategies for successful distance education}

With these basic categories in place how does a provider of distance education ensure that successful teaching-learning experiences take place? One strategy is to use the chart provided to make the best possible match-up of delivery system, learner and instructor. The second approach is to concentrate on the learner's needs. Let us take an example of a course delivered by direct broadcast satellite. As shown in the chart availability is medium, maintainability is high and compatibility is high. This means that the purchase and installation of the satellite equipment is not too difficult. The equipment is probably not easily maintained by the instructor or learner, thus requiring outside support, but the system is fairly compatible with other existing equipment. With respect to economic issues, start-up cost for the delivery of instruction is high and ongoing cost of the delivery is average. The system requires a large critical mass in order to be productive and the sender is required to provide most of the support, while the receiver is required to provide little support. Regarding the information flow issues the system provides high visual and auditory information, but very little kinaesthetic interaction. This would mean that the system might not be the best method for teaching how to do a gymnastic routine on the parallel bars or how to high jump, but might work well for a foreign language or science course. The system also might not be good for visually impaired students, if visuals are used extensively without adequate audio supplements. Several examples of this type of system are common in today's distance educational environment.

Another example which might not be familiar is to use two-way radio with data capability (packet radio). As can be seen from the overall ratings, twoway radio is a strong candidate for areas with the requirement of low economic outlays while it still provides good technology advantages. Two-way radio systems combined with other cost effective delivery mediums such as mail correspondence, broadcast radio, occasional telephone conferencing or on-site instructor visits can form an instructionally effective package. Such packages have been successfully used in Australia [2], with satellite based two-way radio among the ten member nations of the University of the South Pacific [3] and in 
Micronesia [4]. Adding data capability would be an enhancement to the systems referenced above.

\section{Emphasizing the technology over the learning: a potential pitfall}

It seems that with many modern delivery systems emphasis is placed first on the delivery system and then on the teacher, with little thought given to the unique characteristics of the individual learners. This could be attributable to the fact that system developers have first hand dealings with both the delivery system design and instructor selection. The learner is assumed to be receiving some type of traditional course work, so that a pre-assessment of learner needs is performed and is assumed to be satisfactory. This might be the case if distance education were exactly the same as the traditional classroom. The problem is that distance education is not a $100 \%$ replacement for the traditional classroom. The advantages and disadvantages of distance education delivery systems compared to traditional classrooms must be taken into account in order to provide the necessary teaching adjustment which will then lead to positive learning experience for each student.

\section{Multimodal systems}

Programs which continually involve the student in the course content have been shown to be successful. This raises the level of attention and motivation which keeps the learner from being just a passive participant. Also multimodal systems which incorporate more than one delivery medium, have shown good potential in meeting varied learner needs [5]. By providing more than just video and audio the learner is transported to a new cognitive environment and thus once again becomes active and engaged. Multimodal information dissemination also allows a greater number of learning methods and styles to be supported thus providing better learning opportunities to learners. Another important feature of distance education is that it is well suited for low and high achieving students. Advanced students may be enthusiastic about the prospect of a new, previously unavailable intellectual challenge, while those struggling in a traditional classroom may welcome a new educational approach.

\section{CONCLUSION}

This article has outlined one possible method for classifying distance education systems in order to compare and contrast alternatives to determine optimum configurations. Each system has advantages and disadvantages compared to a traditional classroom environment. Understanding these advantages can help provide the highest potential for learning among 'at a distance' students. If the 
role of distance education is to provide alternate learning opportunities for 'at a distance' students, then the tail must not wag the dog-learners must be the main target for development (as opposed to the curriculum, instructor or delivery system). Unfortunately, because learners change in each course cycle, trade-offs must be made in an industrial model of education in order to provide teaching and learning which is both interchangeable and replicatable. The ultimate question is: does the manufacturing of education need to continue for students who are taught in a production line model? Distance education has the potential to change the current instructional paradigm and give way to a new era in education, much like the communications satellite changed the way we communicate.

Finally it is easy to focus on high-end, high bandwidth applications which are 'new' technology oriented since these types of systems draw technology hungry educators and instructional providers. Having an exciting new system to develop does not necessarily make the system a good learning experience for the student. Many of the systems outlined in this article can be termed 'old' technology, but positive things can be said for using older technology in many areas of instruction as well as many areas of the world which do not possess the necessary technology infrastructure to support these 'new' high technology solutions. Two-way radio, postal mail and other tried and trued distance educational delivery systems should not be ruled out when defining a distance education system. The combination of older and newer technology makes for stronger systems as well as providing redundancy within the system.

\section{REFERENCES}

1. Jones, G. and Knezek, G. (1993) Non-Commercial Radio/Satellite Telecommunications: Affordable Options for Technology Educators. Proceedings of the Tenth International Conference on Technology and Education. Cambridge, Massachusetts, USA, Vol 2, pp. 701-703.

2. Lange, J., Casey, R., Dunqua, B., Dunnet, C., Knezek, G., Flanigan, J., Flavel, E., Houlton, E., Livingston, K., Seumahu, S., Scannell, P. and Spooner, P. (1984) ATS-1: Social Service Satellite Networks in the Pacific. Proceedings of the Sixth Pacific Telecommunications Conference. Honolulu: Pacific Telecommunications Council, pp. 109-118.

3. Miller, J. K. (1982) Evaluation and Guidelines for Future Use. Proceedings of the Fourth Pacific Telecommunications Conference. Honolulu: Pacific Telecommunications Council. 
4. Porter, K. (1981) Using Satellite for Course Delivery in the Pacific: A Northern Marianas Experiment. Proceedings of the Third Pacific Telecommunications Conference. Honolulu: Pacific Telecommunications Council.

5. Southworth, J.H., Flanigan, J.M., and Knezek, G. (March 1981) Computers in Education: International Multi-Node Electronic Conferencing Honolulu. The Printout, pp. 8-13. 